\title{
Kinetic Analysis of the Chemical Processes in the Decomposition of Gaseous Dielectrics by a Non-Equilibrium Plasma - Part 1: $\mathrm{CF}_{4}$ and $\mathrm{CF}_{4} / \mathrm{O}_{2}$.
}

\author{
Glauco F. Bauerfeldt and Graciela Arbilla* \\ Departamento de Físico-Química, Instituto de Química, Universidade Federal do Rio de Janeiro, \\ Sala 408, CT Bloco A, Cidade Universitária, 21949-900, Rio de Janeiro - RJ, Brazil
}

\begin{abstract}
A integração numérica das equações diferenciais ordinárias que descrevem um sistema cinético e a análise de sensibilidade dos resultados aos parâmetros são metodologias cada vez mais utilizadas na cinética química. Neste trabalho, é apresentado um estudo de simulação numérica da decomposição em fases gasosa de $\mathrm{CF}_{4}$ e de misturas $\mathrm{CF}_{4} / \mathrm{O}_{2}$ na presença de silício. É analisada a importância relativa dos processos individuais e são calculados os coeficientes de sensibilidade e o efeito da incerteza nos parâmetros. Os resultados são comparados com dados experimentais da literatura para ajustar os parâmetros do modelo. O principal agente de corrosão neste sistema é o flúor atômico. As concentrações das principais espécies $\left(\mathrm{SiF}_{4}, \mathrm{CO}, \mathrm{CO}_{2}\right.$ e $\left.\mathrm{COF}_{2}\right)$ dependem da composição da mistura.
\end{abstract}

Numerical integration of the coupled differential equations which describe a chemical reacting system and sensitivity analysis are becoming increasingly important tools in chemical kinetics. In this work, a numerical modelling analysis of the chemical processes in the gas-phase decomposition of pure $\mathrm{CF}_{4}$ and $\mathrm{CF}_{4} / \mathrm{O}_{2}$ mixtures, in the presence of silicon, was performed. The relative importance of individual processes was analysed and the sensitivity coefficients as well as the effect of the parameters uncertainties were determined. The results were compared with experimental data from the literature to adjust the model parameters. The main etching agent in the system is the fluorine atom. The concentrations of the main species $\left(\mathrm{SiF}_{4}, \mathrm{CO}, \mathrm{CO}_{2}\right.$ and $\left.\mathrm{COF}_{2}\right)$ depend on the composition of the mixture.

Keywords: sensitivity analysis, rate of production analysis, $\mathrm{CF}_{4}$ decomposition

\section{Introduction}

Models for the plasma chemistry of $\mathrm{SF}_{6} / \mathrm{O}_{2}$ and $\mathrm{CF}_{4} / \mathrm{O}_{2}$ mixtures have been extensively investigated by different research groups ${ }^{1-18}$. The complexity of the involved processes makes it very difficult to develop and solve a complete model to explain and predict experimental results ${ }^{19,20}$.

Such models should consider the homogeneous processes in the gas phase and the heterogeneous processes occurring at the gas-solid interface. Some aspects, such as free radical chemistry, electron impact dissociation rates for molecules and radicals, electron number density in the plasma, energy distribution for electrons and chemical species and also the need of solving the system in spatial and temporal coordinates, require an exact approach beyond the capabilities of current computational resources.

In this work, we used the submodel approach which is also frequently applied in other areas of kinetic and numeri-

*e-mail: graciela@iq.ufrj.br cal modeling such as atmospheric and combustion chemistry21. Our main goal was to obtain a good description of the principal chemical processes in the gaseous phase and to analyse the relative importance of individual reactions and the parameters influence in the model results by estimating the sensitivity coefficients $S_{i j}$ for the species (i) towards the parameters of the model $\left(\lambda_{j}\right)$. Thus, we constructed chemical submodels in which the other processes are considered in a parameterised, simplified way. The present submodels use a semi-empirical approach in which phenomenological dissociation rates, calculated from the measured conversions of the feed gases in experimental studies, are incorporated and where the analysis is centered on the description of the neutral gas-phase chemistry which occurs in the plasma as the ionic species analysis did not prove relevant ${ }^{18}$.

\section{Formulation of the models}

The models of Edelson and Flamm ${ }^{3}$ and Ryan and Plumb 4,5 were used as a basis for the present kinetic scheme. The complete set was introduced and discussed by Bauerfeldt and 
Arbilla18 in a previous work on the plasma etching of silicon. This set of reactions included surface phenomena as physical adsorption and desorption, as well as surface reactions. The plasma was considered a source of ions and electrons which led to $\mathrm{CF}_{4}$ dissociation and to atomic fluorine production.

Experimental data from Smolinsky and Flamm ${ }^{22}$, were also used to choose the boundary conditions, the parameters of the model and to test the validity of the model results. In that work, the $\mathrm{CF}_{4} / \mathrm{O}_{2}$ mixtures at a total gas number density of $1.6 \times 10^{16} \mathrm{~cm}^{-3}(0.5$ Torr $)$ flowing in a $5 \mathrm{~cm}$ length aluminum tube, were excited by a $49 \mathrm{~W}, 13.56 \mathrm{MHz}$ discharge. The stable products analysis was performed up to $10 \mathrm{~cm}$ downstream from where the discharge started.

The most uncertain aspects in the formulation of this submodel are the electron impact dissociation rate for $\mathrm{CF}_{4}$, the rate constants for gas-phase free radical reactions and the heterogeneous processes. Electron impact dissociation rates can be calculated from estimated electron number density, electron energy distribution and electron impact dissociation cross-section of the interest species. Plumb and Ryan ${ }^{4}$ have made such estimates which are expected to be accurate within one order of magnitude. From measured results 22,23 the dissociation coefficients for $\mathrm{CF}_{4}$ and $\mathrm{O}_{2}$ can be estimated in the experimental conditions. In our model, these values were adjusted as parameters in order to fit the experimental dissociation rates.

For the boundary conditions of our work, a plug flow in a cylindrical tube was assumed. The plasma region of the reactor corresponds to a gas mixture residence time of $2.25 \times 10^{-2} \mathrm{~s}$. The space beyond the plasma region, called afterglow, was also included in the calculations, what leads to a total residence time in the reactor of $4.45 \times 10^{-2} \mathrm{~s}$. The adsorption of gas phase species on the reactor wall and further reaction or desorption to return to the gas phase were considered in a simplified way.

\section{The numerical method}

The set of differential equations were solved using the fourth order Runge-Kutta-Semi-Implicit Method ${ }^{24}$ as implemented in the package KINAL ${ }^{25}$. The relative relevance of each reaction was first evaluated by calculating the contribution of each step to the total rate of concentration change for each species. Then, in order to evaluate the effect of parameters uncertainties on the predicted concentrations, the sensitivity coefficients ${ }^{26}$ were calculated by the Direct Decomposed Method $^{27}$. In addition to the relevance and sensitivity analysis, another test was done by changing some of the parameters within their range of uncertainties. This calculation was necessary as some of the parameters and constants are quite hard to evaluate, such as electron number density, branching ratios and heterogeneous reaction rate coefficients.

\section{Results and Discussion}

As described above, the reaction set used for the sensitivity calculations was previously employed to describe the plasma etching of silicon by pure $\mathrm{CF}_{4}$ and $\mathrm{CF}_{4} / \mathrm{O}_{2}$ mixtures, and can be found in our previous paper ${ }^{18}$. This reaction set was proposed to fit experimental data from Smolinsky and Flamm $^{22}$. Initial conditions for the simulation are listed in Table 1 and are the same as used in reference 18.

Table 1. Numerical simulations initial conditions.

$\begin{array}{ll}\text { Temperature } & 313 \mathrm{~K} \\ \text { Total pressure } & 0.5 \text { Torr } \\ \text { Flow } & 24.37 \mathrm{~cm}^{3} \mathrm{STP} / \mathrm{min} \\ \text { Plasma length } & 5.0 \mathrm{~cm}\end{array}$

Initial Concentrations (molecules $\mathrm{cm}^{-3}$ )

$\begin{array}{ll}\text { Total }[\mathrm{M}] & 1.54 \times 10^{16} \\ {\left[\mathrm{CF}_{3}\right]} & 1.00 \times 10^{10} \\ {[\mathrm{~F}]} & 1.00 \times 10^{10} \\ {[\mathrm{Si}]} & 1.00 \times 10^{14} \\ {\left[\mathrm{CF}_{3(\mathrm{~s})}\right]} & 1.00 \times 10^{10}\end{array}$

\section{Pure $\mathrm{CF}_{4}$}

There is no direct experimental evidence about the branching ratio for $\mathrm{CF}_{4}$ decomposition. Some indirect information may be obtained from $\mathrm{CF}_{4} / \mathrm{O}_{2}$ results, as will be discussed below. Clearly, this ratio is an important parameter of the model. In this work we explored the effect of a wide range of values. Following electron impact, $\mathrm{CF}_{4}$ may dissociate to $\mathrm{CF}_{3}$ and $\mathrm{CF}_{2}$ radicals. In fact these are probably non direct processes. The direct dissociation of $\mathrm{CF}_{4}$ through the reaction:

$\mathrm{e}^{-}+\mathrm{CF}_{4} \rightarrow \mathrm{CF}_{3}+\mathrm{F}+\mathrm{e}^{-}$

proceeds only at high electron energies (12.5 eV threshold $)^{28}$. More recent data 29 show that the alternative reaction:

$\mathrm{e}^{-}+\mathrm{CF}_{4} \rightarrow \mathrm{CF}_{3}+\mathrm{F}^{-}$

is relatively faster and proceeds at lower energies, $5-6 \mathrm{eV}$. This reaction is followed by the rapid detachment reaction:

$\mathrm{e}^{-}+\mathrm{F}^{-} \rightarrow 2 \mathrm{e}^{-}+\mathrm{F}$

This sequence being equivalent to reaction 1 .

In a similar way, it was proposed 30 that $\mathrm{CF}_{2}$ is produced through the rapid dissociation of an excited state of $\mathrm{CF}_{3}$ radical which in turn is formed from $\mathrm{CF}_{4}$ decomposition. In the time scale of the experiments, the $\mathrm{CF}_{2}$ production may be considered a direct process after electron impact of $\mathrm{CF}_{4}$ :

$\mathrm{e}^{-}+\mathrm{CF}_{4} \rightarrow \mathrm{CF}_{2}+2 \mathrm{~F}+\mathrm{e}^{-}$

Branching ratios $\mathrm{k}_{\mathrm{CF} 4} \rightarrow \mathrm{CF}_{2} / \mathrm{k}_{\mathrm{CF} 4} \rightarrow \mathrm{CF} 3$, $\mathrm{k}_{\mathrm{j}}$ being the rate constant for the reaction $\mathrm{j}$, from 14 to zero were tested. 
The best results, when compared with experimental data, are obtained when the primary dissociation of $\mathrm{CF}_{4}$ favours the formation of $\mathrm{CF}_{2}$ by a factor 2.3. Because of that a ratio of 2.4, as estimated by Plumb and Ryan ${ }^{4}$, was used.

Table 2 shows the relative importance of individual reactions, based on a rate of production analysis, for the main gaseous species. The production of $\mathrm{CF}_{2}$ by electron impact of $\mathrm{CF}_{3}$ is a negligible path of reaction for $\mathrm{CF}_{3}$ radicals. Reactions of $\mathrm{CF}_{3}$ with neutral species $\mathrm{F}$ and $\mathrm{F}_{2}$ are the main path of consumption of the radical. Also, at the early stages of reaction, when $\mathrm{F}$ and $\mathrm{F}_{2}$ concentrations are still low, the recombination to $\mathrm{C}_{2} \mathrm{~F}_{6}$ appears an important path.

Our simulations show that the rate of the recombination processes is at least $10^{3}$ times faster than the electron impact dissociation, not included in the final model. Also, since $\mathrm{CF}_{4}$ concentration is $10^{2}-10^{3}$ times greater than $\mathrm{CF}_{3}$ concentration, the direct electron dissociation of $\mathrm{CF}_{3}$ radical is a negligible source of $\mathrm{CF}_{2}$ when compared with $\mathrm{CF}_{4}$ dissociation to produce $\mathrm{CF}_{2}+2 \mathrm{~F}$. A similar situation arises for $\mathrm{CF}_{2}$ radicals. The electron impact dissociation, to give $\mathrm{CF}+\mathrm{F}$, is at least 30 times slower than the recombination reaction of $\mathrm{CF}_{2}$ with $\mathrm{F}$ atoms. Also, $\mathrm{CF}_{2}$ dissociation is a negligible source of $\mathrm{F}$ atoms when compared with the primary $\mathrm{CF}_{4}$ dissociation to produce $\mathrm{CF}_{2}+2 \mathrm{~F}$.

$\mathrm{CF}_{3}$ and $\mathrm{CF}_{2}$ dissociation processes may be included in a more comprehensive reaction set, in order to obtain a better description of the system. Nevertheless, it would not lead to important changes in the results of the model mainly due to the uncertainties in primary dissociation rates and heterogeneous reactions of atoms.

The plasma chemistry is highly influenced by the dissociation and recombination processes of $\mathrm{CF}_{2}$ and $\mathrm{CF}_{3}$. Clearly, the main recombination reaction of $\mathrm{CF}_{3}$ is with $\mathrm{F}$ atom. This fast reaction controls the $\mathrm{CF}_{3}$ concentration and restricts the amount of $\mathrm{CF}_{4}$ consumed to very low values. At the end of the discharge region $(5 \mathrm{~cm}) 96 \%$ of the initial $\mathrm{CF}_{4}$ remains. In the afterglow region, where electron dissociation ceases, the reforming of $\mathrm{CF}_{4}$, through reactions

$\mathrm{CF}_{3}+\mathrm{F}+\mathrm{M} \rightarrow \mathrm{CF}_{4}+\mathrm{M}$

$\mathrm{CF}_{3}+\mathrm{F}_{2} \rightarrow \mathrm{CF}_{4}+\mathrm{F}$

continues and, because of that, a net consumption of $2 \%$ is found at $10 \mathrm{~cm}$.

Table 2. Contribution of individual reactions to kinetic processes in the plasma region.

\begin{tabular}{|c|c|c|c|}
\hline \multirow[t]{2}{*}{ Process } & \multicolumn{3}{|c|}{ Rate (particles $\mathrm{cm}^{-3} \mathrm{~s}^{-1}$ ) } \\
\hline & Pure $\mathrm{CF}_{4}$ & $25 \% \mathrm{O}_{2} / 75 \% \mathrm{CF}_{4}$ & $80 \% \quad \mathrm{O}_{2} / 20 \% \mathrm{CF}_{4}$ \\
\hline Main reactions for $\mathrm{CF}_{2}$ radicals & & & \\
\hline $\mathrm{CF}_{2}+\mathrm{F} \rightarrow \mathrm{CF}_{3}$ & $-3.183 \times 10^{16}$ & $-4.052 \times 10^{14}$ & $-4.963 \times 10^{12}$ \\
\hline $\mathrm{CF}_{2}+\mathrm{O}\left({ }^{3} \mathrm{P}\right) \rightarrow \mathrm{COF}+\mathrm{F}$ & zero & $-2.016 \times 10^{16}$ & $-5.416 \times 10^{15}$ \\
\hline $\mathrm{CF}_{2}+\mathrm{O}\left({ }^{3} \mathrm{P}\right) \rightarrow \mathrm{CO}+2 \mathrm{~F}$ & zero & $-5.760 \times 10^{15}$ & $-1.547 \times 10^{17}$ \\
\hline $\mathrm{CF}_{2}+\mathrm{COF} \rightarrow \mathrm{CO}+\mathrm{CF}_{3}$ & zero & $-3.695 \times 10^{11}$ & $-1.191 \times 10^{9}$ \\
\hline $\mathrm{CF}_{2}+\mathrm{COF} \rightarrow \mathrm{CF}+\mathrm{COF}_{2}$ & zero & $-3.695 \times 10^{11}$ & $-1.191 \times 10^{9}$ \\
\hline Main reactions for $\mathrm{CF}_{3}$ radicals & & & \\
\hline $\mathrm{CF}_{3}+\mathrm{F}+\mathrm{M} \rightarrow \mathrm{CF} 4+\mathrm{M}$ & $-3.904 \times 10^{16}$ & $-1.198 \times 10^{15}$ & $-1.591 \times 10^{13}$ \\
\hline $2 \mathrm{CF}_{3} \rightarrow \mathrm{C}_{2} \mathrm{~F}_{6} *$ & $-7.665 \times 10^{15}$ & $-4.752 \times 10^{11}$ & $-1.7181 \times 10^{9}$ \\
\hline $\mathrm{CF}_{3}+\mathrm{F}_{2} \rightarrow \mathrm{CF}_{4}+\mathrm{F}$ & $-2.142 \times 10^{15}$ & $-1.669 \times 10^{14}$ & $-1.022 \times 10^{12}$ \\
\hline $\mathrm{CF}_{3}+\mathrm{F}^{-} \rightarrow \mathrm{e}^{-}+\mathrm{CF}_{4}$ & $-5.641 \times 10^{2}$ & $-1.753 \times 10^{2}$ & $-1.109 \times 10^{0}$ \\
\hline $\mathrm{CF}_{3}+\mathrm{O}\left({ }^{3} \mathrm{P}\right) \rightarrow \mathrm{COF}_{2}+\mathrm{F}$ & zero & $-9.794 \times 10^{15}$ & $-2.853 \times 10^{15}$ \\
\hline $\mathrm{CF}_{3}+\mathrm{O} 2+\mathrm{M} \rightarrow \mathrm{CF}_{3} \mathrm{O}_{2}+\mathrm{M}$ & zero & $-1.970 \times 10^{14}$ & $-3.782 \times 10^{13}$ \\
\hline $\mathrm{CF}_{3}+\mathrm{COF} \rightarrow \mathrm{CO}+\mathrm{CF}_{4}$ & zero & $-2.703 \times 10^{12}$ & $-9.441 \times 10^{9}$ \\
\hline $\mathrm{CF}_{3}+\mathrm{COF} \rightarrow \mathrm{CF}_{2}+\mathrm{COF}_{2}$ & zero & $-2.703 \times 10^{12}$ & $-9.441 \times 10^{9}$ \\
\hline $\mathrm{CF}_{3} \rightarrow \mathrm{CF}_{3}(\mathrm{~s})$ & $-8.295 \times 10^{14}$ & $-6.531 \times 10^{12}$ & $-3.927 \times 10^{11}$ \\
\hline $\mathrm{CF}_{3}+\mathrm{CF}_{3}(\mathrm{~s}) \rightarrow \mathrm{C}_{2} \mathrm{~F}_{6}(\mathrm{~s})$ & $-9.308 \times 10^{11}$ & $-1.612 \times 10^{8}$ & $-1.233 \times 10^{6}$ \\
\hline Main reactions for $F$ atoms & & & \\
\hline $\mathrm{CF}_{3}+\mathrm{F}+\mathrm{M} \rightarrow \mathrm{CF}_{4}+\mathrm{M}$ & $-3.904 \times 10^{16}$ & $-1.198 \times 10^{15}$ & $-1.591 \times 10^{13}$ \\
\hline $2 \mathrm{~F}+\mathrm{M} \rightarrow \mathrm{F}_{2}+\mathrm{M}$ & $-4.791 \times 10^{15}$ & $-1.099 \times 10^{17}$ & $-5.362 \times 10^{15}$ \\
\hline $\mathrm{CF} 2+\mathrm{F} \rightarrow \mathrm{CF}_{3}$ & $-3.183 \times 10^{16}$ & $-4.052 \times 10^{14}$ & $-4.963 \times 10^{12}$ \\
\hline $\mathrm{F}+\mathrm{COF}+\mathrm{M} \rightarrow \mathrm{COF}_{2}+\mathrm{M}$ & zero & $-1.152 \times 10^{15}$ & $-1.479 \times 10^{13}$ \\
\hline $\mathrm{F}+\mathrm{CO}+\mathrm{M} \rightarrow \mathrm{COF}+\mathrm{M}$ & zero & $-1.564 \times 10^{14}$ & $-9.228 \times 10^{12}$ \\
\hline $\mathrm{F}+\mathrm{O}_{2}+\mathrm{M} \rightarrow \mathrm{FO}_{2}+\mathrm{M}$ & zero & $-5.052 \times 10^{14}$ & $-3.563 \times 10^{14}$ \\
\hline $\mathrm{F}+\mathrm{FO}_{2} \rightarrow \mathrm{F}_{2}+\mathrm{O} 2$ & zero & $-2.087 \times 10^{14}$ & $-1.107 \times 10^{13}$ \\
\hline $\mathrm{F} \rightarrow \mathrm{F}(\mathrm{s})$ & $-8.852 \times 10^{15}$ & $-3.450 \times 10^{16}$ & $-7.620 \times 10^{15}$ \\
\hline $\mathrm{F}+\mathrm{CF}_{3}(\mathrm{~s}) \rightarrow \mathrm{CF} 4(\mathrm{~s})$ & $-9.929 \times 10^{13}$ & $-8.512 \times 10^{12}$ & $-2.390 \times 10^{11}$ \\
\hline $\mathrm{F}+\mathrm{Si} \rightarrow \mathrm{SiF} / \mathrm{Si}$ & $-2.526 \times 10^{5}$ & $-6.350 \times 10^{14}$ & $-3.949 \times 10^{15}$ \\
\hline $\mathrm{F}+\mathrm{SiF} / \mathrm{Si} \rightarrow \mathrm{SiF}_{2} / \mathrm{Si}$ & $-2.526 \times 10^{15}$ & $-6.351 \times 10^{14}$ & $-3.949 \times 10^{15}$ \\
\hline $\mathrm{F}+\mathrm{SiF}_{2} / \mathrm{Si} \rightarrow \mathrm{SiF}_{3} / \mathrm{Si}$ & $-2.526 \times 10^{15}$ & $-6.351 \times 10^{14}$ & $-3.949 \times 10^{15}$ \\
\hline $\mathrm{F}+\mathrm{SiF}_{3} / \mathrm{Si} \rightarrow \mathrm{SiF}_{4} / \mathrm{Si}$ & $-2.526 \times 10^{15}$ & $-6.351 \times 10^{14}$ & $-3.949 \times 10^{15}$ \\
\hline
\end{tabular}


Figures 1 and 2 show the first-order local concentration sensitivity coefficients $S_{i j}$ for the main species towards the parameters of the model.As usual, these coefficients, elements of the local concentration sensitivity matrix, are defined as

$$
S_{i j}=\partial Y_{i} / \partial 1_{j}
$$

were $Y_{i}$ are the concentrations of the chemical species and $\lambda_{j}$ are the parameters of the model. The sensitivity matrix, $\mathbf{S}$, represents a linear approximation of the dependence of the solutions on parameters changes. The change of a parameter belonging to reaction $j$ causes a direct concentration change in those species which are reactants or products in that reaction. Also, the direct concentration changes cause further differences in the concentration of other species. The latter, indirect, effects are non-linear and can not be predicted by screening analysis $25 \mathrm{~b}$. This non-linear effects can be revealed by sensitivity analysis. The information taken from these coefficients is rather different from that taken from the so-called brute force method, where a parameter (for example the electron density) is changed. The $S_{i j}$ values are local, since they belong to a time interval defined by the time of the perturbation $t_{1}$ and the time of the observation $t_{2}$ and, also, they represent the perturbation on a species $i$, while all the others are kept constant. On the other hand, the previous analysis showed the effect of a substantial change on one of the parameters, during the total time of observation $t_{2} 25 \mathrm{~b}$. The information taken from all the analysis done here is complementary and should be considered as a whole in order to assess the relevance and interconnection of parameters and variables and to decide whether a reaction or a chemical species may be eliminated from the model, or not.

The high level of $\mathrm{CF}_{2}$ concentration relative to $\mathrm{CF}_{3}$ is due to two factors: as shown in Figures 1 and 2, $\mathrm{CF}_{2}$ formation through the reaction $\mathrm{e}^{-}+\mathrm{CF}_{4} \rightarrow \mathrm{CF}_{2}+2 \mathrm{~F}+\mathrm{e}^{-}$is faster than $\mathrm{CF}_{3}$ production reactions 1 and

$\mathrm{F}+\mathrm{CF}_{2} \rightarrow \mathrm{CF}_{3}$

by a factor of about 1.5 . Also, the rate of consumption of $\mathrm{CF}_{3}$ by reaction 5 is about 1.2 times greater than that for $\mathrm{CF}_{2}$ recombination reaction 7 .

In the plasma region stable $\mathrm{C}_{2} \mathrm{~F}_{6}$ grows steadily. $\mathrm{CF}_{3}$ recombination reaction to produce the vibrationally excited species $\mathrm{C}_{2} \mathrm{~F}_{6}{ }^{*}$ :

$$
2 \mathrm{CF}_{3} \rightarrow \mathrm{C}_{2} \mathrm{~F}_{6} *
$$

takes account of about $15.5 \%$ of the total lost of $\mathrm{CF}_{3}$ radicals. The model considers the $\mathrm{C}_{2} \mathrm{~F}_{6}$ electron dissociation:

$\mathrm{e}^{-}+\mathrm{C}_{2} \mathrm{~F}_{6} \rightarrow 2 \mathrm{CF}_{3}+\mathrm{e}^{-}$
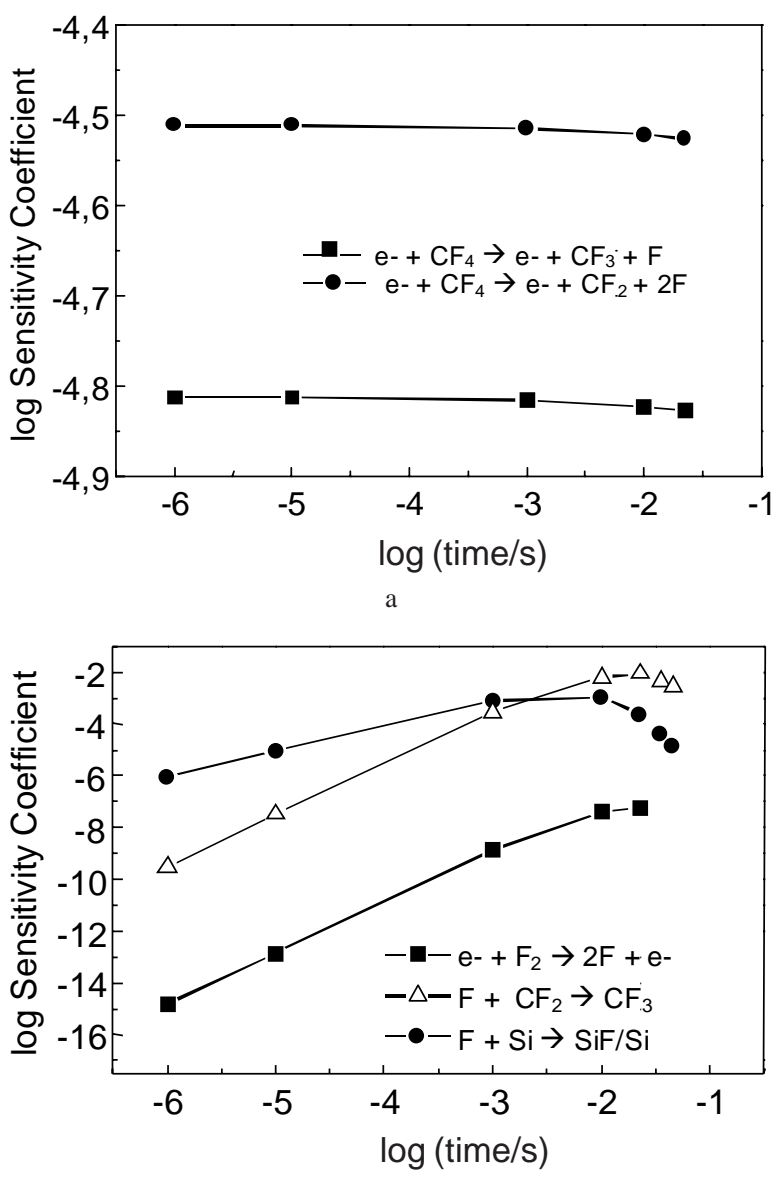

$\mathrm{b}$

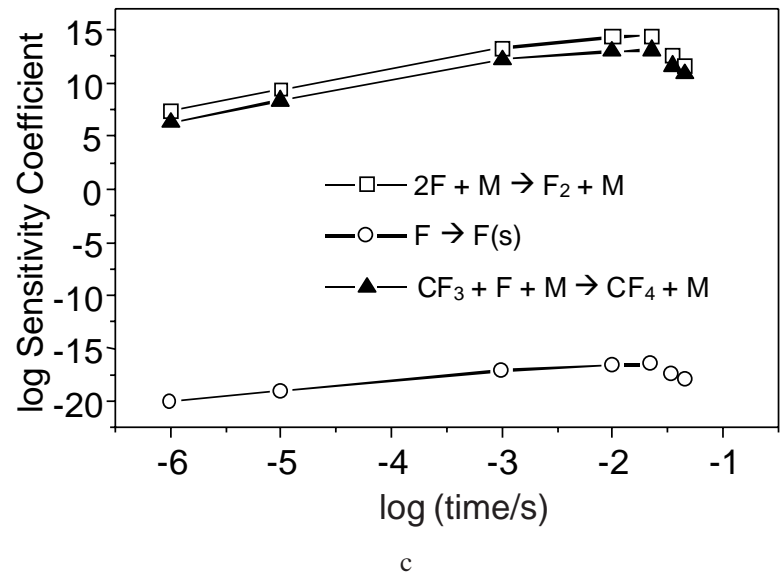

Figure 1. Sensitivity coefficients for atomic fluorine reactions for the plasma etching of silicon in pure $\mathrm{CF}_{4}$ as a function of time.

The dissociation coefficient used by Edelson and Flamm ${ }^{3}$ leads to a considerable reduction of $\mathrm{C}_{2} \mathrm{~F}_{6}$ concentration, since the rate of $\mathrm{C}_{2} \mathrm{~F}_{6}$ electron dissociation is about 0.5 times the rate of $\mathrm{C}_{2} \mathrm{~F}_{6}$ production by $\mathrm{CF}_{3}$ radical recombination. If the rate coefficient of Ryan and Plumb 4,5 , 20 times smaller, is used, the contribution of $\mathrm{C}_{2} \mathrm{~F}_{6}$ electron dissociation reaction drops to virtually zero and $\mathrm{C}_{2} \mathrm{~F}_{6}$ 

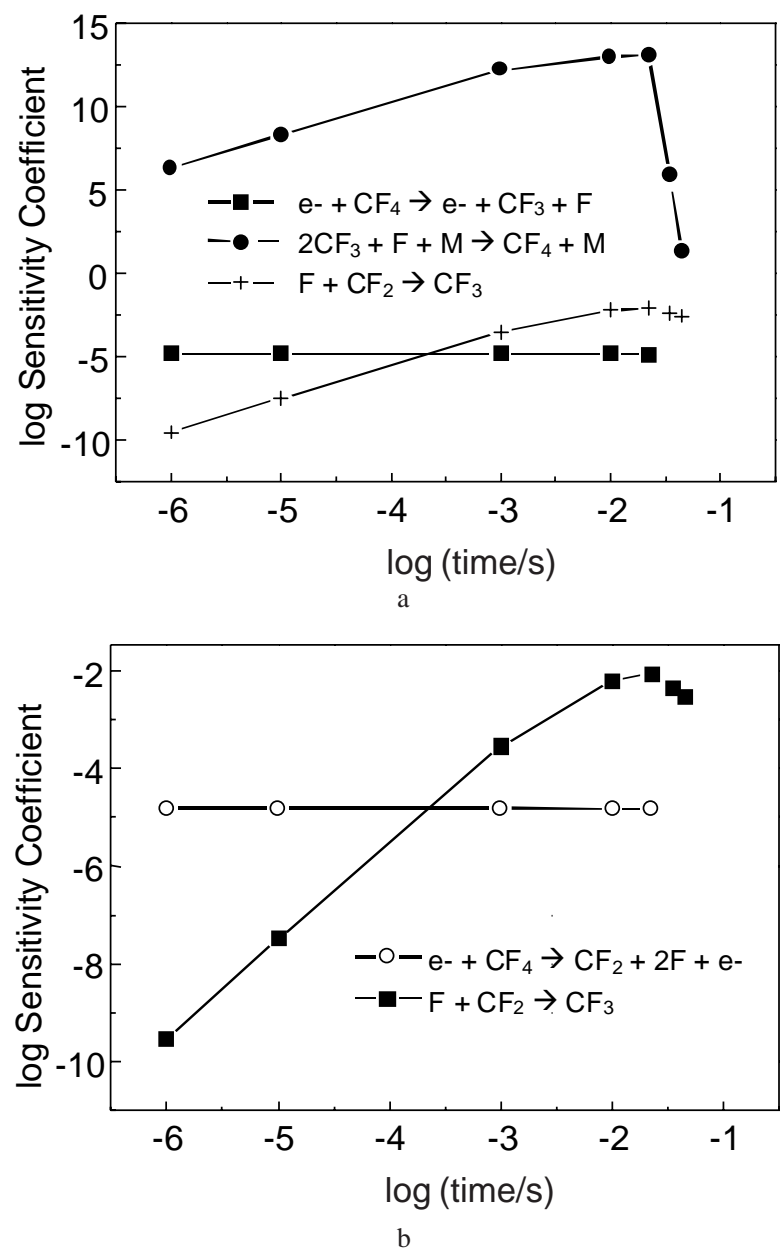

Figure 2. Sensitivity coefficients for $\mathrm{CF}_{3}(2 \mathrm{a})$ and $\mathrm{CF}_{2}$ reactions (2b) for the plasma etching of silicon in pure $\mathrm{CF}_{4}$ as a function of time.

concentration increases by a factor of 2 . Nevertheless, $\mathrm{CF}_{3}$ concentration does not alter significantly since that electron dissociation contributes in about $6 \%$ to its formation.

In the post-discharge region $\mathrm{CF}_{3}$ concentration drops drastically and very little $\mathrm{C}_{2} \mathrm{~F}_{6}$ is further formed. In this region, the main recombination reactions are with $\mathrm{F}$ and $\mathrm{F}_{2}$. Also, in this region a considerable fall of $\mathrm{CF}_{2}$ concentration occurs, mainly because the production of $\mathrm{CF}_{2}$ by $\mathrm{CF}_{4}$ electron dissociation stops and the rapid recombination reaction with $\mathrm{F}$ atoms continues downstream.

The silicon etching process was modelled as a sequence of single $\mathrm{F}$ atom reactions which forms $\mathrm{SiF}_{4}$ on the surface $\left(\mathrm{SiF}_{4}\right)$ $\mathrm{Si}$ ) that subsequently desorbs to the gas phase. The choice of atomic fluorine as the active etching is supported in previous experimental and simulated data ${ }^{1-20}$. As in the previous works 3,5 the first $\mathrm{F}$ atom reaction was chosen as the limiting step in order to emulate experimental results ${ }^{31}$. Silicon was assumed to be uniformly distributed in the reactor. In the presence of $\mathrm{Si}$, the $\mathrm{F}$ atom concentration is reduced in about $10-15 \%$ for a silicon number density of $1 \times 10^{14}$ particles $\mathrm{cm}^{-3}$ and in about $25 \%$ for a silicon number density of $1.6 \times 10^{16}$ particles $\mathrm{cm}^{-3}$. The value of the rate coefficient for:

$\mathrm{F}+\mathrm{Si} \rightarrow \mathrm{SiF} / \mathrm{Si}$

is certainly one of the most uncertain aspects in the formulation of the model. In this work we used the value of Edelson and Flamm ${ }^{3}$ and also the value of Ryan and Plumb 5 , which is smaller by a factor of 4.6. The results for $\mathrm{SiF}_{4}, \mathrm{CF}_{3}, \mathrm{CF}_{2}$ and $\mathrm{F}$ differ in less than $25 \%$ which is not a significant figure when considering the other uncertainties of the model.

Another uncertain parameter of the model is the electron number density in the plasma. The main sources of $\mathrm{F}$ atoms are reaction 1 and 4 which depend on electron number density. The values of Edelson and Flamm ${ }^{3}\left(1 \times 10^{10}\right.$ $\left.\mathrm{cm}^{-3}\right)$ and Ryan and Plumb $5\left(6 \times 10^{10} \mathrm{~cm}^{-3}\right)$ were both tested. The best agreement with experimental results 22 is obtained for an electron number density of $1.0 \times 10^{10} \mathrm{~cm}^{-3}$, a silicon number density of $1.0 \times 10^{14} \mathrm{~cm}^{-3}$ and with a rate constant of $4.61 \times 10^{-13}$ molec $^{-1} \mathrm{~cm}^{3} \mathrm{~s}^{-1}$ for reaction 9 .

The results stress our previous conclusions: the shape of the sensitivity curves follows the general shape of the individual rate curves 18 and the ratio between the $S_{i j}$ values is closely related to the contribution of each reaction

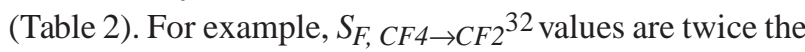
$S_{F, C F 4 \rightarrow C F 3}$ values and are nearly constant within the plasma region (Figure 1a). The $S_{F, j}$ values for the atomic fluorine association reactions with $\mathrm{CF}_{2}$ and $\mathrm{Si}$ (Figure 1b) show that for small residence times, the changes in $\mathrm{F}+\mathrm{Si}$ association rate constant will affect $F$ concentrations more than the changes in $\mathrm{F}+\mathrm{CF}_{2}$ association rate constant. The inverse holds for longer residence times. That is a direct consequence of the contribution of $\mathrm{F}+\mathrm{Si}$ association, on the silicon surface, being more important at the reactor entrance or for short times and the contribution of $\mathrm{F}+\mathrm{CF}_{2}$ association being more important as the $\mathrm{CF}_{2}$ concentration grows up. Also, the $S_{F, j}$ coefficients (Figures $1 \mathrm{~b}$ and 1c) show that the more relevant reactions for atomic fluorine are the production reactions $\mathrm{CF}_{3}+\mathrm{F}$ and $\mathrm{CF}_{2}+\mathrm{F}$ and the recombination to form $\mathrm{F}_{2}$.

Similar results were obtained for $\mathrm{CF}_{2}$ and $\mathrm{CF}_{3}$ sensitivity coefficients. The values for $S_{C F 3, C F 3}+F+M \rightarrow C F 4+$ $M /[M]$ and $S_{C F 3, F+C F 2 \rightarrow C F 3}$ are similar, except in the post discharge region, where changes in $\mathrm{F}+\mathrm{CF}_{2}$ association rate constant should affect more the $\mathrm{CF}_{3}$ concentration (Figure 2a). For $\mathrm{CF}_{2}$ radicals, Figure $2 \mathrm{~b}$, the system is more sensitive to changes in $\mathrm{F}+\mathrm{CF}_{2}$ association rate constant. Because of the non linearity of the system, a perturbation in $\mathrm{CF}_{4}$ electron dissociation rate to give $\mathrm{CF}_{2}+$ $2 \mathrm{~F}$ leads to a rather small change in $\left[\mathrm{CF}_{2}\right]$, which recombines, further, with fluorine atoms. In other words, since $\mathrm{CF}_{2}$ production from $\mathrm{CF}_{4}$ and consumption by association 
with atomic fluorine reactions are coupled, small changes in the former hardly affect the radical concentration.

\section{$\mathrm{CF}_{4} / \mathrm{O}_{2}$ Mixtures}

In our previous work on the plasma etching of silicon by $\mathrm{CF}_{4} / \mathrm{O}_{2}$ mixtures, $\mathrm{F}, \mathrm{CF}_{3}$ and $\mathrm{CF}_{2}$ concentrations dependence on the oxygen concentration was suggested, both in the plasma region and in the afterglow region 18 .

In the presence of oxygen, the $\mathrm{O}$ atoms, which are mainly formed through electron impact dissociation of the molecule:

$\mathrm{e}^{-}+\mathrm{O}_{2} \rightarrow 2 \mathrm{O}\left({ }^{3} \mathrm{P}\right)+\mathrm{e}^{-}$

and

$\mathrm{e}^{-}+\mathrm{O}_{2} \rightarrow \mathrm{O}\left({ }^{3} \mathrm{P}\right)+\mathrm{O}\left({ }^{1} \mathrm{D}\right)+\mathrm{e}^{-}$

compete with $\mathrm{F}$ atom for $\mathrm{CF}_{3}$ and $\mathrm{CF}_{2}$ radicals through reactions:

$$
\begin{aligned}
& \mathrm{CF}_{3}+\mathrm{O}\left({ }^{3} \mathrm{P}\right) \rightarrow \mathrm{COF}_{2}+\mathrm{F} \\
& \mathrm{CF}_{2}+\mathrm{O}\left({ }^{3} \mathrm{P}\right) \rightarrow \mathrm{COF}+\mathrm{F} \\
& \mathrm{CF}_{2}+\mathrm{O}\left({ }^{3} \mathrm{P}\right) \rightarrow \mathrm{CO}+2 \mathrm{~F}
\end{aligned}
$$

The rate constant of $\mathrm{CF}_{2}+\mathrm{O}\left({ }^{3} \mathrm{P}\right)$ reaction is one order of magnitude higher than the rate constant for the $\mathrm{F}+\mathrm{CF}_{2}$ recombination. For the set of rate constants used in this model, the reverse situation holds for $\mathrm{CF}_{3}$.

Thus, in the presence of $\mathrm{O}_{2}$, new intermediates and new products $\left(\mathrm{COF}, \mathrm{COF}_{2}, \mathrm{CO}\right.$ and $\left.\mathrm{CO}_{2}\right)$ appear18 and also the concentration of $\mathrm{F}, \mathrm{CF}_{2}$ and $\mathrm{CF}_{3}$ are controlled by the coupled association and recombination reactions of $\mathrm{CF}_{2}$ and $\mathrm{CF}_{3}$ with either $\mathrm{F}$ or $\mathrm{O}\left({ }^{3} \mathrm{P}\right)$. The relative relevance of reactions with $\mathrm{F}$ and $\mathrm{O}$ atoms changes with the composition of the mixture. For low concentrations of $\mathrm{O}_{2}$, the reactions of $\mathrm{CF}_{2}$ and $\mathrm{CF}_{3}$ with $\mathrm{F}$ atoms become relevant and a significant fraction of $\mathrm{COF}$ is converted to $\mathrm{COF}_{2}$. At high concentrations of $\mathrm{O}_{2}, \mathrm{COF}$ is almost completely oxidised to $\mathrm{CO}_{2}$. The ratio (3.5) between the $\mathrm{O}\left({ }^{3} \mathrm{P}\right)$ reaction with $\mathrm{CF}_{3}$ and $\mathrm{CF}_{2}$ rate constants is slightly higher than the ratio (2.5) between $\mathrm{CO}_{2}$ and $\mathrm{CO}$ concentrations, showing that part of $\mathrm{COF}$ is still reacting with $\mathrm{F}$.

Table 2 compares the rate of sink reactions for $\mathrm{F}, \mathrm{CF}_{2}$ and $\mathrm{CF}_{3}$. The entries of the table show some of the significant differences between the results for pure and oxygenated mixtures. With low concentrations of molecular oxygen, a very significant fraction of $\mathrm{CF}_{2}$ is still converted to $\mathrm{CF}_{3}$ through association with atomic fluorine. The $\mathrm{COF}$ which is formed by reaction of $\mathrm{O}$ atoms with $\mathrm{CF}_{2}$, reacts further with atomic fluorine to produce $\mathrm{COF}_{2}$. Only a minor part of COF reacts with oxygen producing $\mathrm{CO}_{2}$.

At high relative concentrations of molecular oxygen in the feed gas, the $\mathrm{CF}_{2}$ produced in the primary dissociation step reacts exclusively with $\mathrm{O}$ atoms forming $\mathrm{CO}$ and $\mathrm{COF}$ which are rapidly converted to $\mathrm{CO}_{2}$. In the same way, the $\mathrm{CF}_{3}$ is converted rapidly to $\mathrm{COF}_{2}$, which may dissociate to $\mathrm{COF}$ and ultimately $\mathrm{CO}_{2}$ and $\mathrm{CO}$.

Some of the sensitivity coefficients are presented in Figures 3 and 4 . The sensitivity coefficients for the formation reactions (Figures 3a, 3b and 3c) follow the relative importance of individual reactions, that is $S_{F, C F 4 \rightarrow C F 2+2 F}>$ $S_{F, C F 4 \rightarrow C F 3+F} /[M]>S_{F, F 2 \rightarrow 2 F} /[M]$. Also, these $S_{F, j}$ values are higher than values for reactions 13 - 15 (Figure 3c). The $S_{F, j}$ coefficients calculated for the main sink reactions (Figures 3a, 3b and 3c), in the presence of $\mathrm{O}_{2}$, show that in that environment the main atomic fluorine reaction is the self recombination to form $\mathrm{F}_{2}$, as confirmed by Table 2 .

The $S_{F, j}$ coefficients calculated for reactions

$$
\begin{aligned}
& \mathrm{COF}+\mathrm{O}\left({ }^{3} \mathrm{P}\right) \rightarrow \mathrm{CO}_{2}+\mathrm{F} \\
& \text { and } \\
& \mathrm{COF}+\mathrm{F}+\mathrm{M} \rightarrow \mathrm{COF}_{2}+\mathrm{M}
\end{aligned}
$$

follow the same trend, the ratio between them being approximately the $[\mathrm{M}]$ value (Figure $3 \mathrm{~d}$ ). For the $75 \% \mathrm{CF}_{4} /$ $25 \% \mathrm{O}_{2}$ mixture, the $S_{F, C O F+O(3 P) \rightarrow C O 2+F}$ value is about 15 times the $S_{F, C O F+F \rightarrow C O F 2} /[M]$ since the COF , which is formed by reaction of $\mathrm{O}$ atoms with $\mathrm{CF}_{2}$, reacts with $\mathrm{O}$ to produce $\mathrm{CO}_{2}$, rather than with $\mathrm{F}$, to produce $\mathrm{COF}_{2}$. For these plasmas where the $\mathrm{CF}_{4} / \mathrm{O}_{2}$ ratio in the feed gas is higher, the $S_{F, C O F+F \rightarrow C O F 2} /[M]$ becomes relatively higher.

The sensitivity coefficients for $\mathrm{COF}_{2}$ (Figure 4a) and $\mathrm{COF}$ (Figure $4 \mathrm{~b}$ ) confirm that the main path of formation of $\mathrm{COF}_{2}$ is the reaction between $\mathrm{CF}_{3}$ and $\mathrm{O}\left({ }^{3} \mathrm{P}\right)$ atoms, which is about 27 times faster than reaction $17(\mathrm{COF}+\mathrm{F}+$ $\mathrm{M}$ à $\left.\mathrm{COF}_{2}+\mathrm{M}\right)$. Finally, in the plasma region, reaction between $\mathrm{CF}_{2}$ and $\mathrm{O}\left({ }^{3} \mathrm{P}\right)$ to form $\mathrm{COF}$ :

$\mathrm{CF}_{2}+\mathrm{O}\left({ }^{3} \mathrm{P}\right) \rightarrow \mathrm{COF}+\mathrm{F}$

is about 16 times faster than the further reaction of COF with atomic fluorine (reaction 16). This result is also shown by the

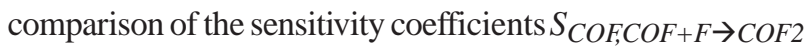
$/[M]$ and $S_{C O F C F 2+O(3 P) \rightarrow C O F+F}$ (Figure 4b). Downstream of the discharge region, atomic oxygen concentration dramatically drops through reactions with $\mathrm{CF}_{2}$ and $\mathrm{COF}$ and the formation of the final product $\mathrm{COF}_{2}$ predominates.

In Figure 5 the rate of formation of gaseous $\mathrm{SiF}_{4}$ as function of the distance from the origin and the mole percent of $\mathrm{O}_{2}$ in the feed is displayed. Since in this model atomic fluorine is the active etching agent and the primary etching reaction was considered rate controlling, the surface in Figure 5 closely reproduces the change in atomic fluorine concentration with distance from the origin and the mole percent of $\mathrm{O}_{2}$ in the feed ${ }^{18}$. 

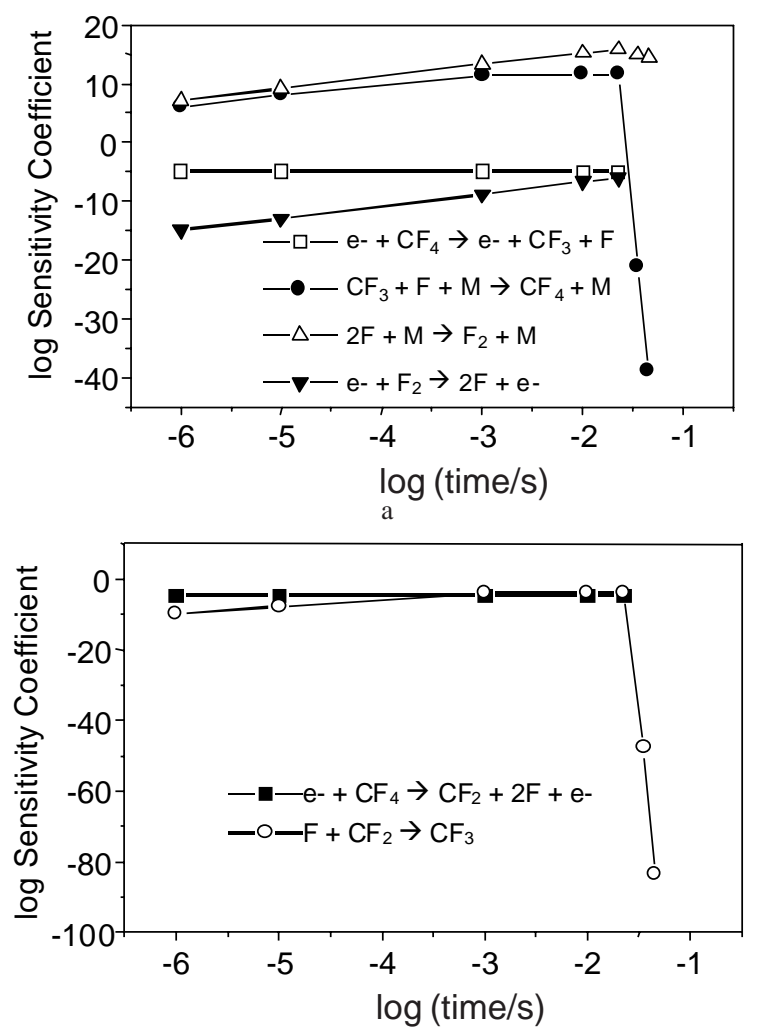

b

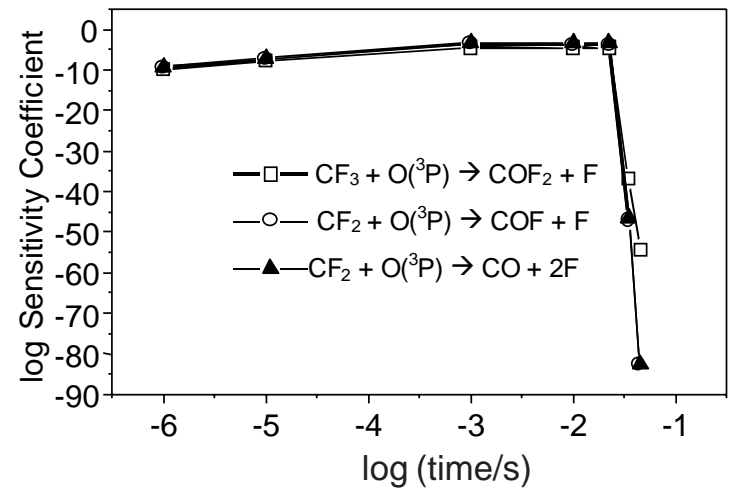

c

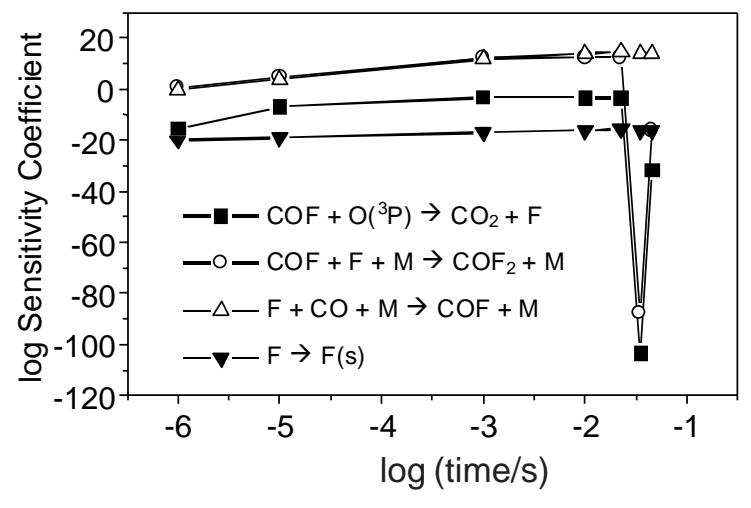

d

Figure 3. Sensitivity coefficients for atomic fluorine reactions for the plasma etching of silicon in a mixture $75 \% \mathrm{CF}_{4}$ and $25 \% \mathrm{O}_{2}$ as a function of time.
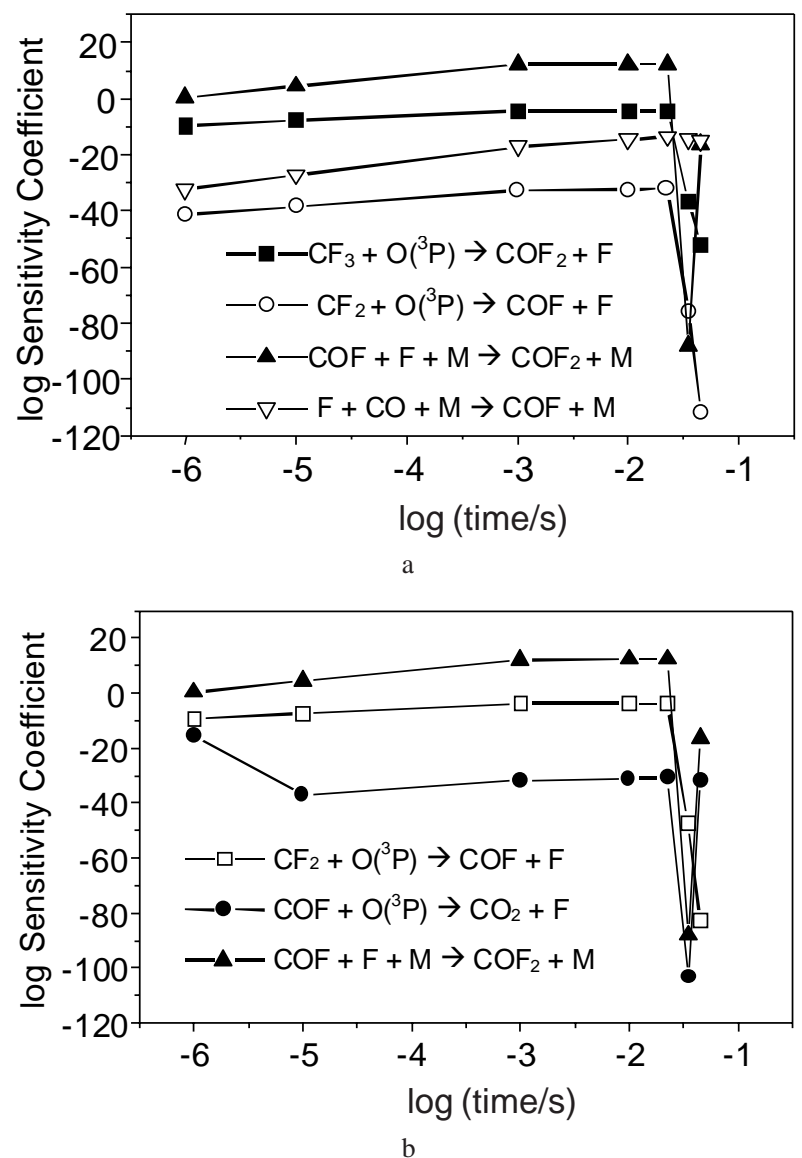

Figure 4. Sensitivity coefficients for $\mathrm{COF}_{2}$ (4a) and $\mathrm{COF}$ (4b) reactions for the plasma etching of silicon in a mixture $75 \% \mathrm{CF}_{4}$ and $25 \% \mathrm{O}_{2}$ as a function of time.

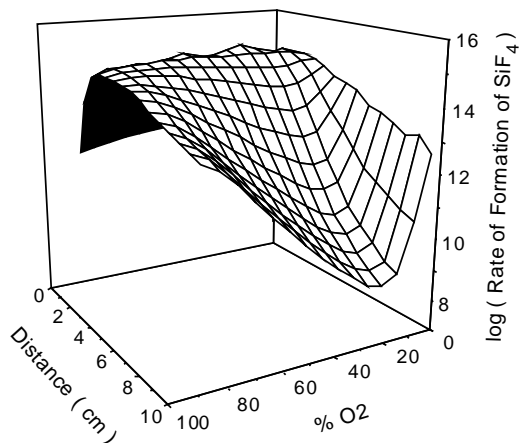

Figure 5. Rate of formation of gaseous $\mathrm{SiF}_{4}$ as a function of the distance from the discharge origin and the mole percent of $\mathrm{O}_{2}$ in the feed.

\section{Conclusions}

The main goal of this work was to analyse the chemical processes in the plasma decomposition of $\mathrm{CF}_{4}$ and $\mathrm{CF}_{4} / \mathrm{O}_{2}$ mixtures in the presence of silicon. The rate of production and sensitivity analysis, as well as the computed concentrations, show that the major features of plasma etching of silicon are explained in terms of gas-phase reactions. For this system, positive and negative ionic species were also 
considered, and incorporated to the model using literature experimental rate coefficients. The results showed that reactions involving these species are not important in determining the gas phase chemistry.

The model reproduces the experimental conclusion that atomic fluorine is the active etching agent. The fact that the primary etching reaction appears to be the most significant process and the sequential fluorination reactions have no significant sensitivities, is due to the fact that their rates were purposely chosen not to be rate-controlling.

For a complex system with significant uncertainties, such as this, the more important contribution of modelling is to demonstrate, through the rate of production and the sensitivity analysis, which reactions require further experimental or theoretical investigation.

The importance analysis shows that many key processes are poorly known and need a better determination. The major uncertainties in the gas phase chemistry are the branching ratios for the primary dissociation processes, the cross sections for electron impact dissociation and the electron number densities.

The extension of these chemical sub-models to more complete models will involve a better determination of the surface chemistry and the transport of radicals and ions, which were crudely parameterised in this work. The formulation of a complete model must also involve the consideration of the energy distribution of particles and temperature gradients. These results may be considered as an extension of previous chemical models and provide forward insight into the chemical processes details.

\section{Acknowledgements}

The authors thank partial financial support from $\mathrm{CNPq}$ and FAPERJ. They also thank Prof. T. Turányi (Central Research Institute of Chemistry, Budapest, Hungary) for a free copy of KINAL package and Prof. Gerardo Gerson B. de Souza (DFQ/IQ/UFRJ) for his interest in this project.

\section{References}

1. Mogab, C. J.; Adams, A. C.; Flamm, D. L. J. Appl. Phys. 1976, 49 , 3796.

2. Kushner, M. J. J. Appl. Phys. 1982, 53 , 2923.

3. Edelson, D.; Flamm, D. L. J. Appl. Phys. 1984, 56, 1522.

4. Plumb, I. C.; Ryan, K. R. Plasma Chem. Plasma Process. 1986, 6, 205.

5. Ryan, K. R.; Plumb, I. C. Plasma Chem. Plasma Process. 1986, 6, 233.

6. Plumb, I. C.; Ryan, K. R. Plasma Chem. Plasma Process. 1986, $6,247$.

7. Kline, L.E. IEEETrans. Plasma Sci. 1986, PS-14 , 145.
8. Anderson, H. M.; Merson, J. A.; Light, R. W. IEEE Trans. Plasma Sci. 1986, PS-14, 156.

9. Venkatesan, S. P.; Trachtenberg, I.; Edgard, T. F. J. Electrochem. Soc. 1987, $134,3194$.

10. Ryan, K. R. Plasma Chem. Plasma Process. 1989, 9, 483.

11. Economou, D. J.; Park, S. K.;Williams, G. J. Electrochem. Soc. 1987, $134,3194$.

12. Venkatesan, S. P.; Edgard, T. F.; Trachtenberg, I. J. Electrochem. Soc. 1989, 136, 536.

13. Ryan, K. R.; Plumb, I. C. Plasma Chem. Plasma Process. 1990, $10,207$.

14. Lii, Y. J.; Jorné, J.; Cadien, K. C.; Schoenholtz Jr., J. E. J. Electrochem. Soc. $1990,137,3633$.

15. Park, S. K.; Economou, D. J. J. Electrochem. Soc. 1991, 138, 1499.

16. Kopalidis, P. M.; Jorné, J. J. Electrochem. Soc. 1993, 140,3037

17. Khairallah, Y.; Khonsari-Arefi, F.; Amouroux, J. Pure Appl. Chem. 1994, 66, 1353.

18. Bauerfeldt, G. F.; Arbilla, G. Quím. Nova 1998, 21, 25.

19. Manos, D. M.; Flamm, D. L. Plasma Etching: An Introduction; Academic Press; San Diego, CA, 1989.

20. Ryan, K.R.; Plumb, I.C.; Crit. Rev. Solid State Mater. Sci. 1988, 15, 153.

21. Finlayson-Pitts, B. J.; Pitts Jr., J. S. Atmospheric Chemistry: Fundamentals and Experimental Techniques; John Willey \& Sons ; New York, 1986.

22. Smolinsky, G.; Flamm, D. L. J. Appl. Phys. 1979, 50, 4982.

23. d'Agostino, R.; Flamm, D. L. J. Appl. Phys. 1981, 52, 162.

24. Kaps, P.; Rentrop, P. Numer. Math. 1979 , 33, 55.

25. (a) Turányi, T. Comput. Chem. 1990, 14, 3, 253. (b) Turányi, T. J. Math. Chem. 1990, 5, 203.

26. (a) Steinfeld, J. I.; Francisco, J. S.; Hase, W. L. Chemical Kinetics and Dynamics; Prentice Hall, Englewood Cliffs; New Jersey, 1989. (b) Pilling, M. J.; Smith, I. W. M. Modern Gas Kinetics. Theory, Experiment andApplication Blackwell Scientific Publications; Oxford, 1987. (c) Hirst, D. M. A ComputationalAproach to Chemistry; Blackwell Scientific Publications; Oxford, 1990.

27. Valkó, P.; Vajda, S. Comput. Chem. 1984, 8, 255.

28. Winters, H. F.; Inokuti, M. Phys. Rev. 1982, A25, 1420.

29. Hunter, S. R.; Christophorou, L. G. J. Chem. Phys. 1984, 80,6150 .

30. Flamm, D. L. J. Appl. Phys. 1980, 51, 5688.

31. Flamm, D. L. Donnelly, V. M. Plasma Chem. Plasma Process. 1981, 1, 317.

32. In this work, the symbol $\mathrm{S}_{\mathrm{F}, \mathrm{CF} 4 \rightarrow \mathrm{CF} 2}$ is used to indicate the sensitivity coefficient of species $\mathrm{i}=\mathrm{F}$ towards the rate constant for reaction e- $+\mathrm{CF}_{4} \rightarrow \mathrm{CF}_{2}+2 \mathrm{~F}+\mathrm{e}-\mathrm{A}$ similar nomenclature is used for the other $\mathrm{S}_{\mathrm{ij}}$ coefficients. 